\title{
Complete Radiologic Response in an Anaplastic Oligodendroglioma Treated with Temozolomide and Bevacizumab
}

\author{
Artur Katz Aknar Calabrich \\ Gustavo dos Santos Fernandes Yana Augusta Sakis Novis \\ Centro de Oncologia, Hospital Sírio-Libanês, São Paulo, Brazil
}

\section{Key Words}

Brain neoplasms · Targeted therapies · Anaplastic oligodendroglioma · Temozolomide · Bevacizumab

\begin{abstract}
In this case report, we describe a rare case of a 32-year-old man who presented a highly aggressive, fast growing anaplastic oligodendroglioma five years after being treated with whole brain radiotherapy for a CNS recurrence of a lymphoblastic lymphoma. Initially, the patient was submitted to a surgical intervention and partial tumor resection, which allowed us to establish the pathologic diagnosis and the presence of a $1 \mathrm{p}$ deletion. Shortly after the operation the tumor grew back, exerting important mass effect. Since no radiation therapy or surgery could be used and the patient faced a critical condition, chemotherapy was started with a combination of temozolomide and bevacizumab. Immediately after the first cycle a marked clinical and radiological improvement was documented.
\end{abstract}

\section{Background}

Oligodendroglial tumors have generated a large amount of interest over the past years due to their heightened response to chemotherapy and ability to be divided into prognostic subgroups based on molecular biology [1]. Several clinical studies demonstrated that losses of portions of chromosomes $1 \mathrm{p}$ and $19 \mathrm{q}$ are associated with the oligodendroglial phenotype and longer recurrence-free survival following radiation and/or chemotherapy [2,3]. It is believed that these chromosome regions contain tumor suppressor genes that block the development and/or progression of the tumor. Radiation 


\begin{tabular}{|c|c|c|c|}
\hline $\begin{array}{c}\text { Cose Reports in } \\
\text { Bnatily }\end{array}$ & $\begin{array}{l}\text { Case Rep Oncol 2009;2:57-60 } \\
\text { D0I: } 10.1159 / 000208378\end{array}$ & Published online: March 14, 2009 & $\begin{array}{l}\text { (c) } 2009 \text { S. Karger AG, Basel } \\
\text { ISSN } 1662-6575 \\
\text { www.karger.com/cro }\end{array}$ \\
\hline
\end{tabular}

therapy inducing secondary oligodendroglial tumors are very rare [4], the approximate cumulative risk for secondary brain tumors after cranial irradiation is 1-3\% [5]. Only a small portion of these rare tumors correspond to oligodendroglial histology; there have been less than 10 cases reported to date [4].

\section{Case Report}

A 32-year-old man was admitted to the Hospital Sírio-Libanês in June 2008 with a short history of progressive headache and left hemiplegia. The patient had a previous history of a lymphoblastic lymphoma with central nervous system involvement, and had been previously submitted to a variety of systemic chemotherapy regimens, including an autologous bone marrow transplantation in June 2002. Six months after that procedure the patient developed a CNS recurrence and was treated with radiation therapy which encompassed the whole brain and the neuraxis (24 Gy administered in 12 fractions), achieving a complete remission. The patient remained well and asymptomatic, without any clinical or radiological evidences of lymphoma up until shortly prior to this hospital admission, when a brain MRI was performed, showing a gross mass in the right temporal lobe (fig. 1a, b). A partial tumor resection was carried out and the pathologic evaluation, based on histology and immunohistochemistry, ruled out the possibility of recurrence of the lymphoma and revealed the presence of an anaplastic oligodendroglioma. The pathologic specimen was reviewed by 3 different pathologists, who concurred with this diagnosis. A FISH assay was performed and showed the presence of $1 p$ deletion, but not $19 q$ deletion. During the postoperative period the patient developed a rapid neurologic deterioration (PS:4, complete left hemiplegia, severe headaches). As shown in the MRI performed after the surgical procedure, the tumor had rapidly increased in size (fig. 1c, d). Given the dramatic clinical course and tumor development, we decided to treat the patient with temozolomide at a dose of $150 \mathrm{mg} / \mathrm{m}^{2} /$ day for 5 consecutive days every 28 days associated with bevacizumab at a dose of $10 \mathrm{mg} / \mathrm{kg}$ given on days 1 and 15 . Shortly after the treatment was started, the patient's neurological condition markedly improved. Six weeks after starting this therapy the patient was walking with the help of a cane and the MRI showed a complete resolution of the mass effect and a complete disappearance of the contrast-enhancing tumor (fig. 1e, f).

\section{Discussion}

The classic treatment for patients with a newly-diagnosed anaplastic oligodendroglial tumor is based on maximal surgical resection consistent with preservation of neurologic function [6]. Radiotherapy should be used in patients with large residual mass or with anaplastic lesions [7]. For selected cases with deletions in $1 \mathrm{p}$ and 19q, chemotherapy should also be considered, either in conjunction with radiotherapy or as a single modality $[7,8]$. In our patient the usual approach could not be applied. An adequate tumor resection was not possible because of the size and location of the tumor, which also involved the contralateral hemisphere. In addition, radiation therapy was also not an option due to whole brain irradiation previously administered.

Temozolomide is a broadly utilized oral methylating agent. The activity of this drug in the treatment of high grade gliomas is well recognized. In phase II trials, temozolomide as single agent produces response rates of $50-60 \%$ in patients with anaplastic oligodendroglioma $[9,10]$. There are no randomized trials evaluating the role of temozolomide in oligodendroglial tumors.

Bevacizumab is a monoclonal antibody with important anti-angiogenic properties, which inhibits the serum vascular endothelial growth factor (VEGF), a cystine-knot growth factor involved in vasculogenesis. In phase II trials, bevacizumab showed important activity and safety in patients with high-grade glioma $[11,12]$. Recent data suggest that the combination of temozolomide and Bevacizumab is active in high-grade 


\begin{tabular}{|c|c|c|c|}
\hline $\begin{array}{l}\text { Cose Reports in } \\
\text { Encisily }\end{array}$ & $\begin{array}{l}\text { Case Rep Oncol 2009;2:57-60 } \\
\text { D0I: } 10.1159 / 000208378\end{array}$ & Published online: March 14, 2009 & $\begin{array}{l}\text { @ } 2009 \text { S. Karger AG, Basel } \\
\text { ISSN 1662-6575 } \\
\text { www.karger.com/cro }\end{array}$ \\
\hline
\end{tabular}

gliomas with an acceptable safety profile even when given with concomitant radiotherapy $[13,14]$.

The quick and significant tumor reduction seen in this patient constitutes, to our knowledge, the first report of the use of this form of therapy in an anaplastic oligodendroglioma patient. Given the previous medical history of this patient and the rapid pace of tumor growth, we were afraid that unless the initial treatment could induce important and fast tumor regression, a life-threatening condition would be reached within a matter of days.

Fig. 1. Seriated MRI analysis showing tumor progression and reduction over time. a, b Exam performed on 17/07/08 showing a large mass compromising temporal, parietal and occipital lobes on the T1 contrasted sequence (a) and on the flair sequence (b). c, d Exam performed on 04/08/08 showing a marked increase in tumor size in a short interval, on the contrasted T1 sequence (c) and on the flair sequence (d). e, f Exam performed on 15/09/08, 2 weeks after the second dose of temozolomide was administered, showing a complete disappearance of the contrast-enhancing mass and resolution of the mass effect on the contrasted T1 sequence (e) and on the flair sequence (f).
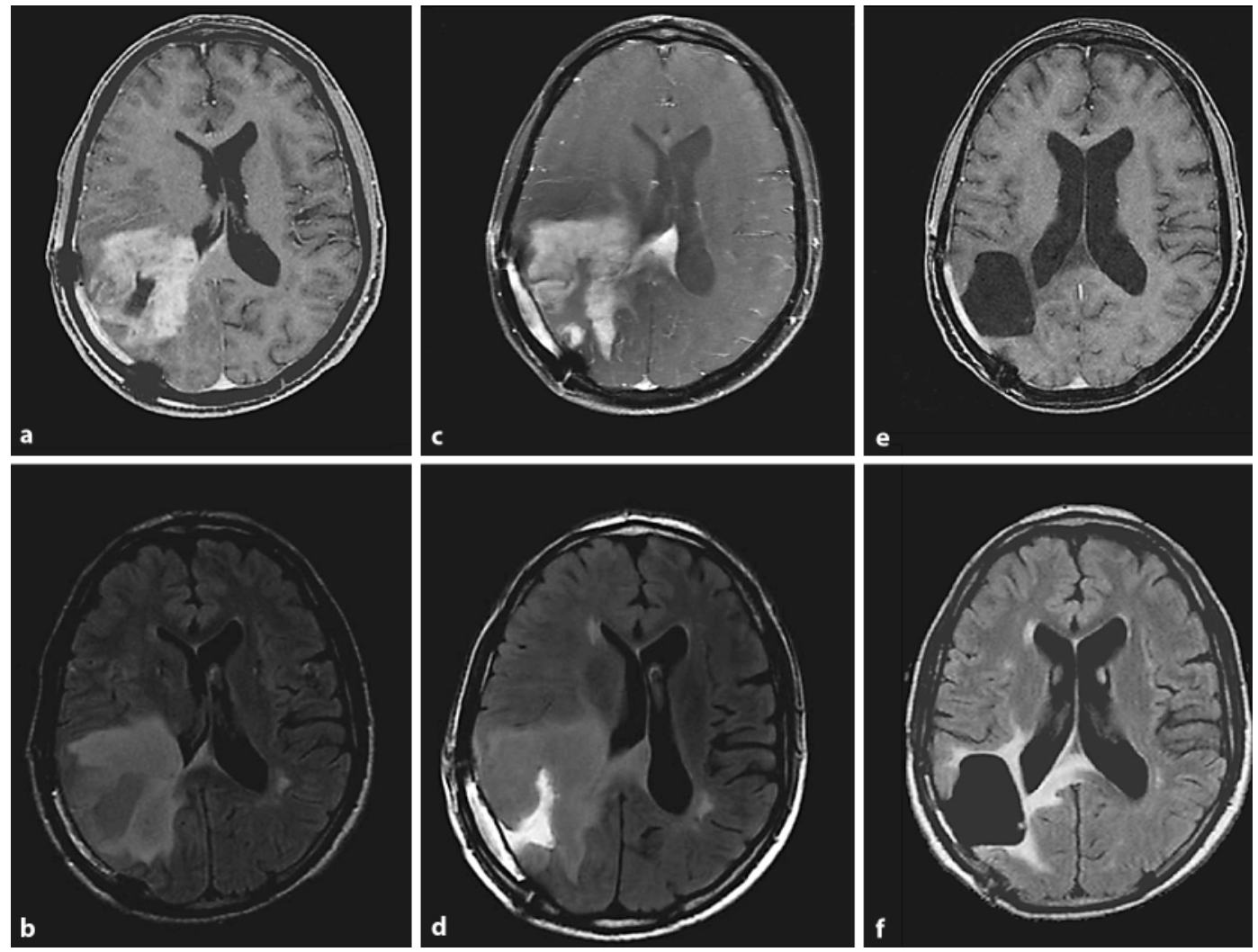


\begin{tabular}{|c|c|c|c|}
\hline $\begin{array}{c}\text { Case Reports in } \\
\text { incill }\end{array}$ & $\begin{array}{l}\text { Case Rep Oncol 2009;2:57-60 } \\
\text { DOI: } 10.1159 / 000208378\end{array}$ & Published online: March 14, 2009 & \begin{tabular}{|l} 
@) 2009 S. Karger AG, Basel \\
ISSN 1662-6575 \\
www.karger.com/cro
\end{tabular} \\
\hline
\end{tabular}

\section{References}

1 Engelhard HH, Stelea A, Cochran EJ: Oligodendroglioma: pathology and molecular biology. Surg Neurol 2002;58:111-117; discussion 117.

-2 Smith JS, Perry A, Borell TJ, et al: Alterations of chromosome arms 1p and 19q as predictors of survival in oligodendrogliomas, astrocytomas, and mixed oligoastrocytomas. J Clin Oncol 2000;18:636-645.

-3 van den Bent MJ, Looijenga LH, Langenberg K, et al: Chromosomal anomalies in oligodendroglial tumors are correlated with clinical features. Cancer 2003;97:1276-1284.

4 Doskaliyev A, Yamasaki F, Kenjo M, et al: Secondary anaplastic oligodendroglioma after cranial irradiation: a case report. J Neurooncol 2008;88:299-303.

5 Fouladi M, Gilger E, Kocak M, et al: Intellectual and functional outcome of children 3 years old or younger who have CNS malignancies. J Clin Oncol 2005;23:7152-7160.

6 Sanai N, Berger MS: Glioma extent of resection and its impact on patient outcome. Neurosurgery 2008;62:753-764; discussion 264-266.

7 Cairncross G, Berkey B, Shaw E, et al: Phase III trial of chemotherapy plus radiotherapy compared with radiotherapy alone for pure and mixed anaplastic oligodendroglioma: Intergroup Radiation Therapy Oncology Group Trial 9402. J Clin Oncol 2006;24:2707-2714.

-8 van den Bent MJ, Carpentier AF, Brandes AA, et al: Adjuvant procarbazine, lomustine, and vincristine improves progression-free survival but not overall survival in newly diagnosed anaplastic oligodendrogliomas and oligoastrocytomas: a randomized European Organisation for Research and Treatment of Cancer phase III trial. J Clin Oncol 2006;24:2715-2722.

9 Brandes AA, Tosoni A, Cavallo G, et al: Correlations between O6-methylguanine DNA methyltransferase promoter methylation status, $1 \mathrm{p}$ and $19 \mathrm{q}$ deletions, and response to temozolomide in anaplastic and recurrent oligodendroglioma: a prospective GICNO study. J Clin Oncol 2006;24:4746-4753.

10 van den Bent MJ, Taphoorn MJ, Brandes AA, et al: Phase II study of first-line chemotherapy with temozolomide in recurrent oligodendroglial tumors: the European Organization for Research and Treatment of Cancer Brain Tumor Group Study 26971. J Clin Oncol 2003;21:2525-2528.

-11 Vredenburgh JJ, Desjardins A, Herndon JE 2nd, et al: Phase II trial of bevacizumab and irinotecan in recurrent malignant glioma. Clin Cancer Res 2007;13:1253-1259.

-12 Vredenburgh JJ, Desjardins A, Herndon JE 2nd, et al: Bevacizumab plus irinotecan in recurrent glioblastoma multiforme. J Clin Oncol 2007;25:47224729 .

13 Narayana A, Golfinos JG, Fischer I, et al: Feasibility of using bevacizumab with radiation therapy and temozolomide in newly diagnosed high-grade glioma. Int J Radiat Oncol Biol Phys 2008;72:383-389.

14 Kirkpatrick J, Desjardins A, Vredenburgh JJ, et al: Combination of bevacizumab, a monoclonal antibody to vascular endothelial growth factor (VEGF), and temozolomide: study of cases. J Clin Oncol (Meeting Abstracts) 2006;24:11522. 